\title{
Changes in leaf functional traits of the endangered plant Disanthus cercidifolius var. longipes with plant growth and development
}

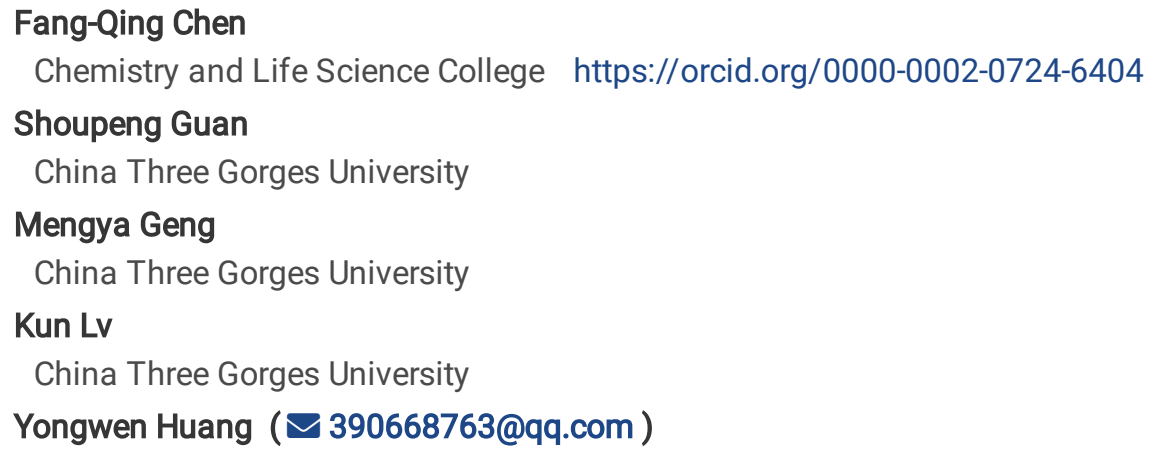




\section{Abstract}

Background: Disanthus cercidifolius var. longipes $\mathrm{H}$. T. Chang is a rare and endangered plant distributed only in the high mountains of southeastern China. In order to reveal the variation in leaf functional traits and plant investment strategies with the change of growth and developmental stages of this species, the leaf functional traits and the trait syndrome including leaf thickness (LT), leaf area (LA), leaf water content (LWC), specific leaf area (SLA), leaf total nitrogen content (LNC), and leaf total phosphorus content (LPC) of plants at different growth and developmental stages were investigated.

Results:The leaf functional traits of the plants significantly differed at different developmental stages. LT and LA of the plants increased during growth and development. LT and LA of the adult plants were $36.65 \%$ and $84.23 \%$ higher than those of the seedlings, respectively. In contrast, SLA, LWC, LNC, and LPC decreased, and in adult plants they were $48.91 \%, 6.63 \%, 8.49 \%$, and $34.66 \%$ lower, respectively, than in seedlings. Principal component analysis showed that as the plants developed, the trait syndrome changed toward increasing LT and LA and decreasing LWC, SLA, LNC, and LPC.

Conclusions:The characteristics of leaf functional traits and trait syndromes changed across different stages of growth and development. The investment strategy changed from fast return to slow return as the plant grew and developed.

\section{Background}

Plant functional traits are a series of plant attributes that potentially affect plant establishment, survival, growth, and death, and are the consequence of the adaptation of plants to environmental conditions during evolution and development (Reich et al., 2003). Combinations of plant functional traits (trait syndrome) determine the life history strategy of plants, which affects the mechanism of coexistence of species. Analysis of the relationship between plant functional traits and plant growth and development may effectively reveal the mechanism of the survival of species (Liu et al., 2015). The leaf is an important organ for photosynthesis, and synthesized organic compounds are the basis for growth and development of plants. The leaf is the most sensitive organ perceiving the change in external resource conditions, especially the changes in light (He et al., 2013). The variation in functional traits reflects, to some extent, the variation in the ability of the plant to acquire light (Zhang et al., 2008). Leaf functional traits mainly include morphological traits, structural traits, and physiological traits. Morphological and structural traits are closely related to physiological traits such as the photosynthetic rate and hydraulic conductivity, which reflect the functional relationship between plants and environmental factors such as light, water, and soil fertility (Sun et al., 2017). At present, the study of leaf functional traits mainly focuses on the relationship among functional traits of adult plants (Yang et al., 2012) or the variation of leaf functional traits in different species and along different gradients of environments (Ding et al., 2011). Those studies revealed the diversity of species and the mechanisms of species responding to environmental changes. Nevertheless, few studies have explored the relationship between plant leaf traits and plant growth and development by investigating the dynamic change in leaf functional traits at different developmental stages (Hu et al., 2014). The endangerment of a species is caused by the weakened or even blocked processes of growth and development due to some environmental stresses (Chen et al., 2005). Studying the variation of leaf functional traits in endangered species at different growth stages is helpful for revealing the variation regularity of the trait syndrome during plant growth and development (Gen et al., 2019), which may provide a reference for the protection of endangered species.

Disanthus cercidifolius var. longipes $\mathrm{H}$. T. Chang is a perennial deciduous shrub of the genus Disanthus in the family Hamamelidaceae. The plants are 2-6 $\mathrm{m}$ tall, grow in broad-leaved evergreen forests and coniferous and broad-leaved mixed forests in areas with an altitude of 600-1100 m, and are tolerant to wet and shade condition. The leaves emerge in early April and fall in late October (Wei, 2015). The species has a narrow distribution region and is found only in some areas of Jiangxi, Zhejiang, and Hunan provinces in China. It is a second-class protection tree species in China (Zhang et al., 2013). At present, research on the ecology of D. cercidifolius var. longipes mainly involves flora characteristics and the genetic diversity of the populations (Wei, 2015; Gao et al., 2013; Liao 2010). Thus far, there is no report on functional trait variation with development. Based on a field investigation, we selected four D. cercidifolius var. longipes communities in Jiangxi province and measured the leaf functional traits at different developmental stages to reveal the variation regularity of the leaf functional traits and trait syndrome during growth and development. The regulatory effect of the development of individuals on the intraspecific economic spectrum of this species was studied, and the status of growth and development of each community was analyzed. Our results may provide a reference for the management of this endangered species. 


\section{Results}

\section{Characteristics of leaf functional traits at different developmental stages}

One-way ANOVA showed that the developmental stage had significant effects on the functional traits of the leaves $(L T: F=88.44, P<$ 0.01; $L A: F=36.42, P<0.01$; SLA: $F=176.19, P<0.01$; LWC: $F=6.62, P<0.05 ; L N C: F=9.68, P<0.01 ; L P C: F=18.65, P<0.01)(F i g .1)$. The order of LT and LA at different developmental stages was seedling < sapling < adult plant, which indicated that LT and LA increased with the increase in the developmental stage, and the LT and LA of adult plants were $36.65 \%$ and $84.23 \%$ higher, respectively, than those of seedlings. In contrast, the order of SLA, LWC, LNC and LPC at different developmental stages was seedling > sapling > adult plants, which meant that the value of the traits decreased with plant development. The SLA, LWC, LNC and LPC values of adult plants were $48.91 \%, 6.63 \%, 8.49 \%$, and $34.66 \%$ lower, respectively, than those of the seedlings.

\section{Correlation Between Developmental Stages And Leaf Functional Traits}

Correlation analysis showed that the correlation between leaf functional traits and developmental stages of the plants growing in different sampling plots was not different (Table 2). The LT and LA of the plants in different sampling plots were positively correlated with the developmental stage $(P<0.05)$, while LWC, SLA and LPC were negatively correlated with development $(P<0.05)$. The LNC of the plants in sampling plots 3 and 4 showed a negative correlation with the developmental stage $(P<0.05)$, while there was no correlation between LNC and the developmental stages of the plants in sampling plots 1 and $2(P>0.05)$. The results indicated that with the increase in growth and developmental stage, the LT and LA of the plants increased, while the LWC, SLA and LPC decreased. LNC showed an overall decreasing trend with increasing development; the reduction was significant in sampling plots 3 and 4, but was not significant in sampling plots 1 and 2 . 
Table 1

Environmental information of plots

\begin{tabular}{|c|c|c|c|c|c|c|c|c|}
\hline \multirow[t]{2}{*}{ Plot } & \multirow[t]{2}{*}{ Location } & \multirow[t]{2}{*}{ Coordinate } & \multirow{2}{*}{$\begin{array}{l}\text { Altitude } \\
\text { (m) }\end{array}$} & \multicolumn{3}{|c|}{ Soil nutrients } & \multirow{2}{*}{$\begin{array}{l}\text { Coverage } \\
(\%)\end{array}$} & \multirow{2}{*}{$\begin{array}{l}\text { Dominant } \\
\text { species }\end{array}$} \\
\hline & & & & $\begin{array}{l}\text { Total } \\
\text { nitrogen } \\
(\mathrm{g} / \mathrm{kg})\end{array}$ & $\begin{array}{l}\text { Total } \\
\text { phosphorus } \\
(\mathrm{g} / \mathrm{kg})\end{array}$ & $\begin{array}{l}\text { Soil } \\
\text { water } \\
\text { content } \\
\text { (\%) }\end{array}$ & & \\
\hline 1 & $\begin{array}{l}\text { Qilichuan, } \\
\text { Jingangshan } \\
\text { city }\end{array}$ & $\begin{array}{l}26^{\circ} 47^{\prime} 09.06^{\prime \prime} \mathrm{N} \\
113^{\circ} 54^{\prime} 06.79 " \mathrm{E}\end{array}$ & 579 & $\begin{array}{l}2.39 \pm \\
0.02 \mathrm{~b}\end{array}$ & $\begin{array}{l}0.80 \pm \\
0.06 a\end{array}$ & $\begin{array}{l}24.05 \\
\pm 0.62 a\end{array}$ & 90 & $\begin{array}{l}\text { Disanthus } \\
\text { cercidifolius var } \\
\text { Longipes, } \\
\text { Cunninghamia } \\
\text { lanceolata, } \\
\text { Hicriopteris } \\
\text { glauca, } \\
\text { Woodwardia } \\
\text { japonica }\end{array}$ \\
\hline 2 & $\begin{array}{l}\text { Jingangshan } \\
\text { natural } \\
\text { conservation } \\
\text { zone, } \\
\text { Jingangshan } \\
\text { city }\end{array}$ & $\begin{array}{l}26^{\circ} 33^{\prime} 06.13^{\prime \prime} \mathrm{N} \\
114^{\circ} 11^{\prime 2} 23.12^{\prime \prime} \mathrm{E}\end{array}$ & 851 & $\begin{array}{l}2.88 \pm \\
0.29 \mathrm{ab}\end{array}$ & $\begin{array}{l}0.83 \pm \\
0.12 \mathrm{a}\end{array}$ & $\begin{array}{l}32.87 \\
\pm 5.53 a\end{array}$ & 80 & $\begin{array}{l}\text { Disanthus } \\
\text { cercidifolius var } \\
\text { Longipes, } \\
\text { Schima } \\
\text { superba, } \\
\text { Cyperus iria }\end{array}$ \\
\hline 3 & $\begin{array}{l}\text { Junfengshan, } \\
\text { Wuzhou city }\end{array}$ & $\begin{array}{l}27^{\circ} 11^{\prime} 49.98 " \mathrm{~N}, \\
116^{\circ} 21^{\prime 2} 29.54^{\prime \prime}\end{array}$ & 1102 & $\begin{array}{l}3.38 \pm \\
0.15 a\end{array}$ & $\begin{array}{l}1.33 \pm \\
0.20 \mathrm{a}\end{array}$ & $\begin{array}{l}16.22 \\
\pm 5.56 a\end{array}$ & 85 & $\begin{array}{l}\text { Disanthus } \\
\text { cercidifolius var } \\
\text { Longipes, } \\
\text { Cyclobalanopsis } \\
\text { gracilis), } \\
\text { Woodwardia } \\
\text { japonica }\end{array}$ \\
\hline 4 & $\begin{array}{l}\text { Junfengshan, } \\
\text { Wuzhou city }\end{array}$ & $\begin{array}{l}27^{\circ} 12^{\prime} 37.71 " \mathrm{~N}, \\
116^{\circ} 20^{\prime} 59.27^{\prime \prime} \mathrm{E}\end{array}$ & 1281 & $\begin{array}{l}2.54 \pm \\
0.28 \mathrm{~b}\end{array}$ & $\begin{array}{l}0.91 \pm \\
0.22 \mathrm{a}\end{array}$ & $\begin{array}{l}17.05 \\
\pm 3.94 a\end{array}$ & 90 & $\begin{array}{l}\text { Disanthus } \\
\text { cercidifolius var } \\
\text { Longipes, } \\
\text { Rhododendron } \\
\text { latoucheae, } \\
\text { Woodwardia } \\
\text { japonica }\end{array}$ \\
\hline
\end{tabular}

Table 2

Pearson correlation coefficients between leaf functional traits and developmental stages $(n=155)$

\begin{tabular}{|c|c|c|c|c|c|c|}
\hline Plot & LT & LA & LWC & SLA & LNC & LPC \\
\hline 1 & $0.808 * \star$ & $0.605^{\star \star}$ & $-0.604^{\star \star}$ & $-0.620 * \star$ & -0.263 & $-0.371^{\star}$ \\
\hline 2 & 0.750 ** & $0.679 * \star$ & $-0.240 *$ & $-0.872^{\star \star}$ & -0.114 & $-0.759 \star \star$ \\
\hline 3 & $0.662^{\star \star}$ & 0.678 ** & -0.466 ** & $-0.749 \star \star$ & $-0.543^{\star *}$ & $-0.907 \star \star$ \\
\hline 4 & 0.436 ** & $0.809 * *$ & $-0.876^{\star \star}$ & $-0.927 * \star$ & $-0.653^{\star \star}$ & $-0.929 * \star$ \\
\hline
\end{tabular}

\section{Variation of the leaf functional trait syndrome at different developmental stages}


The component matrix is shown in Table 3. The absolute values of the correlation coefficients of LA, LT, SLA, LNC, and LPC to the first principal component were high, and the correlation coefficient between LWC and the second principal component was high. Moreover, all of the leaf functional traits were significantly correlated with the two principal components $(P<0.05)$.

Table 3

Factor matrix and principal component contribution rate of leaf functional traits

\begin{tabular}{|llll|}
\hline Index & Principal component 1 & Principal component 2 & Communality \\
\hline LWC & $0.42^{\star \star}$ & $0.86^{\star \star}$ & 0.92 \\
\hline LA & $-0.80^{\star \star}$ & $0.38^{\star \star}$ & 0.79 \\
\hline LT & $-0.81^{\star \star}$ & $0.23^{\star}$ & 0.70 \\
\hline LNC & $0.67^{\star *}$ & $0.19^{*}$ & 0.49 \\
\hline LPC & $0.75^{\star \star}$ & $-0.27^{\star \star}$ & 0.63 \\
\hline SLA & $0.79 \star *$ & $0.26^{\star \star}$ & 0.70 \\
\hline Eigenvalue & 3.11 & 1.11 & \\
\hline Contribution rate $(\%)$ & 51.8 & 18.5 & \\
\hline Cumulative contribution rate $(\%)$ & 51.8 & 70.3 & \\
\hline
\end{tabular}

The PCA ordination of leaf functional traits of the plants at different developmental stages was computed (Fig. 2). The result showed that LWC was the dominant trait in the trait syndrome at the seedling stage. LPC, LT and LA were the dominant traits at the sapling stage. LT and LA were the dominant traits at the adult plant stage. Figure 2 shows that as the plants developed, the trait syndrome changed along axis 1 toward the negative direction, namely, the trait syndrome changed toward increasing LT and LA and decreasing LWC, SLA, LNC and LPC.

\section{Discussion}

\section{Variation of leaf functional traits at different developmental stages}

Different leaf functional traits characterize different functional properties (Liu and Ma, 2015). LA reflects the light capture capacity of the plants (Xiao et al., 2004). LWC reflects the active degree of leaf metabolism to some extent (Cornelissen et al., 2003). LT reflects the ability of leaves to acquire resources and preserve water (Bei et al., 2011). SLA reflects the ability to acquire and use nutrients (Xiao et al., 2004). LNC and LPC reflect the level of N and P metabolism in plants (Hu et al., 2014). Leaf functional traits vary at different stages of growth and development, which have specific characteristics at different times (He et al., 2013). Yang et al. (2016) studied Populus euphratica and Yao et al. (2013) studied mono maple (Acer mono Maxim.) and found that the leaf functional traits were different with respect to the growth characteristics at different developmental stages. In our study, the leaf functional traits of $D$. cercidifolius var. longipes also varied with the developmental stages. LA and LT increased, while LWC, SLA, LNC, and LPC decreased with the increase in plant development, which indicated that LA and LT were positively correlated with the developmental stages, while LWC and SLA were negatively correlated with the developmental stages.

The variation in the traits was closely related to the physiological characteristics at different stages of growth and development. With an increase in age, plants increase their LA so as to assimilate and produce more organic substances to meet their needs for growth and development. An increase in LA enhances transpiration, so plants increase LT to increase the distance and resistance of water transport from inside to the surface of the leaf (Ackerly et al., 2002) so as to reduce water loss (Ding et al., 2014). The increase in LT also promotes the formation of more ducts, cellulose, and lignin, which form a strong support frame and satisfy the needs of the plant to develop from seedlings to adults (Roderick et al., 1999). LWC is at a high level at the seedling and sapling stage due to considerable growth and a high metabolic rate. At the adult plant stage, as the transpiration area increases and other physiological activities such as flowering and reproduction are underway, LWC decreases in order to increase water use efficiency (PérezHarguindeguy et al., 2013). The decrease in SLA with the increase in development may be due to the need for more skeletal structures in large leaves (Duan et al., 2017). At the seedling stage, due to limited resources, it is difficult for the plant to support the large scale 
and long return cycle of construction in the leaves per unit area; as a result, the LA is small, and the SLA is high. At the adult stage, it is more difficult for the plant to transport water to the top of the stem. The water potential at the top of an adult plant is usually lower than that of seedlings, which leads to lower SLA and LWC of the top leaves of the adult plants so as to avoid dysregulation of cell turgor pressure (Liu et al., 2006; Li et al., 2013).

The $\mathrm{N}$ and $\mathrm{P}$ contents of plant leaves often show large variations at different stages (Zheng et al., 2014). The LNC and LPC of plant leaves gradually decrease with an increase in leaf age (Hu et al., 2014). The LNC and LPC also decreased with the development of D. cercidifolius var. longipes. This may be due to the fact that the metabolism in leaves is at a high level at the seedling stage; in addition, growth requires high amounts of protein and nucleic acid, which increases the $\mathrm{N}$ and $\mathrm{P}$ concentrations. By contrast, in saplings and adult plants, most of the nutrients acquired by the plant are transported to other organs to meet the reproduction requirement; as a result, the $\mathrm{N}$ and $\mathrm{P}$ contents in the leaves of the adult plants decrease (Poorter et al., 2009).

\section{Relationship Between Trait Syndrome And Developmental Stages}

In recent years, biologists have considered the leaf functional traits as the consequence of the coordinated collaboration of the components in a complex developmental system (Niinemets et al., 2007), which ultimately embodies varied growth strategies and life history strategies (Niinemets, 2002). Plant leaf traits do not work alone (Kenzo et al., 2015). Once all individual traits show a difference at different developmental stages, the trait syndrome naturally differs among different stages. According to the plant economic spectrum theory, the variation in most plant functional traits is in a covariant or trade-off relationship, which can be classified as the single axis of "fast return-slow return" (Li et al., 2017; Hu et al., 2014). The fast return end is mainly characterized by higher LWC, SLA, LNC, and LPC. The slow return end embodies higher LT and LA. Plant growth and development are generally at the expense of metabolic decline (Wu et al., 2002); hence, compared with seedlings, adult plants have a slow return strategy (Xie et al., 2003), the manifestation of which is that the SLA, LNC, and LPC of seedlings are higher than those of adult plants (Wright et al., 2004; Reich et al., 2014; Díaz et al., 2016).

The PCA in our study showed that the correlation coefficient between the first component and leaf traits LA, LT, SLA, LNC, and LPC was the highest, while the correlation coefficient between the second principal component and LWC was the highest. The PCA results of Disanthus cercidifolius var. longipes plants at different developmental stages showed that LWC was the dominant trait in the trait syndrome at the seedling stage. At the sapling stage, LPC, LT and LA were the dominant traits. At the adult plant stage, LT and LA were the dominant traits in the trait syndrome. With an increase in the plant developmental stage, the trait syndrome of $D$. cercidifolius var. longipes changed along the principal component axis 1 toward the direction with a negative value, which meant that LT and LA increased, while LWC, SLA, LNC, and LPC decreased, indicating that the plants changed from a fast return strategy (resource acquisition) to a slow return strategy (resource conservation). The results of our study support the conclusion that the growth and development of individual plants have a regulatory effect on the economic spectrum of the species (Sendall et al., 2013).

Disanthus cercidifolius var. longipes plants have different economic strategies at different developmental stages, and proper culture and protection measures should be taken according to their requirement at different developmental stages. Seedlings of D.

cercidifolius var. longipes require high LWC. It has been reported that LWC and the photosynthetic rate of the leaves of D. cercidifolius var. longipes seedlings increase with increased shading (Mason et al., 2013), indicating that a humid and shady environment is suitable for the growth of seedlings. Therefore, during relocation of the seedlings, shading is needed to ensure and promote their growth. At the sapling and adult plant stages, LT and LA gradually increase, and plants need strong light for photosynthesis. Therefore, for local or relocated saplings and adult plants, the surrounding trees should be properly trimmed and the debris removed to guarantee the light required by D. cercidifolius var. longipes plants.

\section{Conclusions}

In this study, four D. cercidifolius var. longipes communities in Jiangxi province in China were selected as research objects. The characteristics of leaf functional traits and trait syndromes including leaf thickness (LT), leaf area (LA), leaf water content (LWC), specific leaf area (SLA), leaf total nitrogen content (LNC), and leaf total phosphorus content (LPC) were investigated. These characteristics and the way they changed across different stages of growth and development were analyzed. Results showed there to be significant differences in leaf functional traits of $D$. cercidifolius var. longipes at different developmental stages. LT and LA increased with growth and development, while SLA, LWC, LNC, and LPC decreased. With the development of D. cercidifolius var. 
longipes plants, the trait syndrome changed toward increasing LT, LA and decreasing LWC, SLA, LNC, and LPC. This indicated that the investment strategy changed from fast return to slow return as the plant grew and developed. In order to promote plant growth and development, D. cercidifolius var. longipes seedlings should be properly shaded to ensure their demand for water, while plants near young and adult trees should be properly pruned to meet their need for light.

\section{Methods}

\section{Overview of the areas}

Four endangered communities of D. cercidifolius var. longipes in Jinggang Mountain city and Fuzhou city in Jiangxi Province were selected for investigation (Table 1). This area has a subtropical monsoon climate. The average annual temperature ranges between 14.2 and $17{ }^{\circ} \mathrm{C}$. The lowest temperature ranges from -10 to $-6{ }^{\circ} \mathrm{C}$, and the highest temperature from 38 to $39^{\circ} \mathrm{C}$. The average annual precipitation ranges from 1852.6 to $1875 \mathrm{~mm}$. The soil type is acidic yellow soil. The typical vegetation in the area is subtropical evergreen broadleaf forests. The present main communities are forests of Pinus massoniana (Lamb.) and Cunninghamia lanceolata (Lamb.) Hook. (Xie et al., 2014). The dominant species in the studied communities are D. cercidifolius var. longipes, Schima superba Gardn. et Champ., and Woodwardia japonica (L. f.) Sm.

\section{Sampling Of Plant Leaves}

In August 2018, data were collected from four sampling plots selected in Jinggang Mountain and Junfeng Mountain. In each community of $D$. cercidifolius var. longipes, 10 adult plants (plant height $>3 \mathrm{~m}$ ), 10 saplings (plant height $1-2 \mathrm{~m}$ ), and 15 seedlings (0.3-1 m in height) were selected (Li et al., 2014; Xie et al., 2016). Ten leaves from each adult plant and sapling and 5 leaves from each seedling were collected from the eastern, western, southern, and northern sides, and the top of plants; the leaves grew outside the canopy, were fully spread, and grew well. For each community, a total of 275 leaves were collected, of which 100 leaves were collected from adult plants, 100 leaves from saplings, and 75 leaves from seedlings. The collected leaves were placed between two pieces of wet filter paper, sealed in a ziplock bag, and transported to the laboratory for measurement.

\section{Determination Of Leaf Functional Traits}

The leaf thickness (LT), leaf area (LA), leaf water content (LWC), specific leaf area (SLA), leaf total nitrogen content (LNC) and leaf total phosphorus content (LPC) were determined. The collected leaves were placed in water and kept in the dark at $5{ }^{\circ} \mathrm{C}$ for $12 \mathrm{~h}$. Then, the water on the leaf surface was quickly removed with filter paper, and an electric balance with an accuracy of $0.01 \mathrm{~g}$ was used to weigh the saturated fresh weight of leaves. An electric vernier caliper with an accuracy of $0.01 \mathrm{~mm}$ was used to measure LT. Three spots on a leaf were selected for measuring, which were evenly spaced along the main vein, and each was about $0.25 \mathrm{~cm}$ from the main vein; the average value measured from the 3 spots was used as the LT of a leaf (Cornelissen et al., 2003). The LA data were obtained by scanning the leaves with the WinRHIZO Root Analysis System (Regent Instruments Inc., Canada). After scanning, the leaves were dried at $105^{\circ} \mathrm{C}$ for $15 \mathrm{~min}$, then dried at $60^{\circ} \mathrm{C}$ for $72 \mathrm{~h}$, and weighed to obtain the dry weight of the leaves (PérezHarguindeguy et al., 2013). Data calculation included the following equations: LWC = [(saturated fresh weight - leaf dry weight) (g) / saturated fresh weight $(\mathrm{g})] \times 100 \%, \mathrm{SLA}=\mathrm{LA}\left(\mathrm{m}^{2}\right)$ / leaf dry weight $(\mathrm{kg})$ (Xie et al., 2016). Finally, the leaf samples of the same plant were pulverized and screened through a 100-mesh sieve, and the LNC and LPC of the leaves were measured by using a SAN ++ Continuous Flow Analyzer (Skalar, the Netherlands) (Bei et al., 2011). The measurement of each sample was repeated 3 times.

\section{Data analysis}

SPSS 22.0 software was used for data analysis. The arithmetic mean of leaf trait data was used as the trait value of the leaf. Oneway ANOVA was used to analyze the difference in leaf functional traits at different developmental stages in four sampling plots, and the significance of the differences was tested using Tukey post hoc test $(a<0.05)$. Pearson correlation analysis was used to test the correlation between functional traits and developmental stages (seedling stage, sapling stage, and adult plant stage). Principal component analysis (PCA) of individual leaf functional traits was conducted (the principal component was extracted according to rule of an eigenvalue greater than 1). The positional variation of the trait syndrome at different stages on the principal component 
axis was examined. Since the leaves were collected at the developmental stage designated by plant height, the average plant height was used as the value of the developmental stage.

\section{Abbreviations}

LT, leaf thickness; LA, leaf area; LWC, leaf water content; SLA, specific leaf area; LNC, leaf total nitrogen content; LPC, leaf total phosphorus content.

\section{Declarations}

\section{Acknowledgements}

The authors thank Xiangqiang Tan, Danwei Xiong, Lin Xiang for assistance with field measurements. Yubin Wang undertook the formal identification of the samples and provide details of voucher specimens deposited. We thank the Jinggangshan Nature Reserve for the research permission.

\section{Authors' contributions}

FQC, YWH, SPG and MYG conceived the project; SPG and MYG performed field and laboratory work and analyzed data; all authors contributed to writing; all authors have read and approved the final manuscript.

\section{Funding}

This work was supported by grants from the National Program on Basic Research Project of China (2015FY1103002) and National Key Research and Development Program of China (2017YFC0504904).

\section{Availability of data and materials}

The datasets generated during this study are available from the corresponding author on reasonable request.

\section{Ethics approval and consent to participate}

We conducted our study with approval of Jinggangshan Nature Reserve, Jiangxi Province, China. The study complied with the Convention on International Trade in Endangered Species of Wild Fauna and Flora (CITES).

\section{Consent for publication}

Not applicable.

\section{Competing interests}

The authors declare that they have no competing interests.

\section{Author details}

1 Hubei International Scientific and Technological Center of Ecological Conservation and Management in the Three Gorges Area, China Three Gorges University, Daxue road 8, Yichang, Hubei Province, P.R. China, 2 Engineering Research Center of Eco-environment in the Three Gorges Reservoir Region邓Ministry of Education, China Three Gorges University, Daxue road 8, Yichang, Hubei Province, P.R. China

\section{References}

1. Ackerly DD, Knight CA, Weiss SB, Barton K, Starmer KP. Leaf size, specific leaf area and microhabitat distribution of chaparral plants: contrasting patterns in species level and community level analyses. Oecologla. 2002; 130: 449-457.

2. Bei MR, Luo XH, Yang HZ. Simultaneous determination of nitrogen, phosphorus and potassium in rubber leaf samples by AA3 continuous flow analyzer (CFA). Chin J Trop Crop. 2011; 32: 1258-1264. 
3. Chen FQ, Xie ZQ, Xiong GM, Liu YM, Yang HY. Reintroduction and population reconstruction of an endangered plant Myricaria laxiflora in the Three Gorges Reservoir area, China. ACTA Ecol Sin. 2005; 27:1811-1817

4. Cornelissen JHC, Lavorel S, Gamier E, Díaz S, Buchmann N, Gurvich DE, et al. A handbook of protocols for standardized and easy measurement of plant functional traits worldwide. Aust J Bot. 2003; 51: 335-380.

5. Díaz S, Kattge J, Cornelissen JH, Wright IJ, Lavorel S, Dray S, et al. The global spectrum of plant form and function. Nature. 2016; 529(7585): 167-171.

6. Ding J, Wu Q, Yan H, Zhang SR. Effects of topographic variations and soil characteristics on plant functional traits in a subtropical evergreen broad-leaved forest. Biodivers Sci. 2011;19: 158-167.

7. Ding M, Wen ZM, Zheng Y. Scale change and dependence of plant functional traits in hilly areas of the loess region, Shaanxi Province, China. Acta Ecol Sin. 2014; 34: 2308-2315.

8. Duan YY, Song LJ, Niu SQ, Huang T, Yang GH, Hao WF. Variation in leaf functional traits of different-aged Robinia pseudoacacia communities and relationships with soil nutrients. Chin J Appl Ecol. 2017; 28: 28-36.

9. Gao PX, Li MQ, Zhou SX, Liu J, Niu YL, Du Juan, et al. Distribution and current status of the endangered shrub Disanthus cercidifolius longipes. Plant Sci J. 2013; 31: 34-41.

10. He CX, Li JY, Meng P, Zhang JS. Changes of leaf traits and WUE with crown height of four tall tree species. Acta Ecol Sin. 2013; 33: 5644-5654.

11. Houter NC, Pons TL. Ontogenetic changes in leaf traits of tropical rainforest trees differing in juvenile light requirement. Oecologia. 2012; 169: 33-45.

12. Hu YS, Yao XY, Liu YH.The functional traits of forests at different succession stages and their relationship to terrain factors in Changbai Mountains. Acta Ecol Sin. 2014; 34: 5915-5924.

13. Ishida A, Yazaki K, Hoe AL. Ontogenetic transition of leaf physiology and anatomy from seedlings to mature trees of a rain forest pioneer tree, Macaranga gigantea. Tree Physiol. 2005; 25: 513-522.

14. Kenzo T, Inoue Y, Yoshimura M, Yamashita M, Tanaka-Oda A, Ichie T. Height-related changes in leaf photosynthetic traits in diverse Bornean tropical rain forest trees. Oecologia. 2015; 177: 191-202.

15. Kimball S, Funk JL, Spasojevis MJ, Suding Can functional traits predict plant community response to global change? Ecosphere. 2016; 7(12):1-18

16. Li Q, Cao Y, Peng SZ, Chen YM. Seasonal variations of C, N and P stoichiometric characteristics in leaves of two natural secondary forests in Ziwuling forest district. J Soil Water Conserv. 2017; 31: 319-325.

17. Li SJ, Su PX, Zhang HN, Zhou ZJ, Xie TT. Characteristics and relationships of foliar water and leaf functional traits of desert plants. Plant Physiol J. 2013; 49: 153-160.

18. Li XQ, Li LK, Xie GW, Zheng YS, Gao JW, Tan BR, et al. A study on the floristic diversity of the communities with national endangered plant Disanthus cercidifolius longipes. Acta Agr U Jiangxiensis. 2014; 36: 948-957.

19. Liao FY. The physiological characters of Disanthus cercidifolius and its application in the landscape and architecture. North Hortic. 2010; (8): 69-71.

20. Liu JH, Zeng DH, Don Koo Lee. Leaf traits and their interrelationships of main plant species in southeast Horqin Sandy Land. Chin J Ecol. 2006; 25: 921-925.

21. Liu XJ, Ma KP. Plant functional traits - concepts, applications and future directions. Sci Sin Vitae. 2015; 45: 325-339.

22. Mason CM, Mcgaughey S, Donovan LA. Ontogeny strongly and differentially alters leaf economic and other key traits in three diverse helianthus species. Exp Bot. 2013; 64: 4089-4099.

23. Niinemets Ü, Portsmuth A, Tena D, Tobias M, Matesanz S, Valladares F. Do we underestimate the importance of leaf size in plant economics? Disproportional scaling of support costs within the spectrum of leaf physiognomy. Ann Bot. 2007; 100: 283-303.

24. Niinemets Ü. Is there a species spectrum within the worldwide leaf economics spectrum? Major variations in leaf functional traits in the Mediterranean sclerophyll Quercus ilex. New Phytol. 2015; 205: 79-96.

25. Niinemets Ü. Stomatal conductance alone does not explain the decline in foliar photosynthetic rates with increasing tree age and size in Picea abies and Pinus sy/vestris. Tree Physiol. 2002; 22: 515-535.

26. Niinemets, PA, Tena D, Tobias M, Matesanz S, Valladares F. Do we underestimate the importance of leaf size in plant economics? disproportional scaling of support costs within the spectrum of leaf physiognomy. Ann Bot. 2007;100: 283-303. 
27. Pérez-Harguindeguy N, Díaz S, Garnier E, Lavorel S, Poorter H, Jaureguiberry P, et al. New handbook for standardised measurement of plant functional traits worldwide. Aust J Bot. 2013; 61:167-234.

28. Poorter H, Niinemets Ü, Poorter L, Wright IJ, Villar R. Causes and consequences of variation in leaf mass per area (LMA): a metaanalysis. New Phytol. 2009; 182: 565-588.

29. Reich PB, Wright IJ, Cavender-Bares J, Craine JM, Oleksyn J, Westoby M. The evolution of plant functional variation: Traits, spectra, and strategies. Int J Plant SCI. 2003; 164(Supp.3): 143-164.

30. Reich PB. The worldwide 'fast-slow' plant economics spectrum: a traits manifesto. J Ecol. 2014; 102: $275-301$.

31. Roderick ML, Berry SL, Noble IR, Farquhar GD. A theoretical approach to linking the composition and morphology with the function of leaves. Funct Ecol. 1999; 13: 683-695.

32. Sendall KM, Reich PB. Variation in leaf and twig CO2 flux as a function of plant size: a comparison of seedlings, saplings and trees. Tree Physiol. 2013; 33: 713-729.

33. Shi Y, Wen ZM, Gong SH. Comparisons of relationships between leaf and fine root traits in hilly area of the loess plateau, Yanhe River basin, Shaanxi Province, China. Acta Ecol Sin. 2011; 31: 6805-6814.

34. Sun M, Tian K, Zhang Y, Wang H, Guan DX, Yue HT. Research on leaf functional traits and their environmental adaptation. Plant Sci J. 2017; 35: 940-949.

35. Thomas SC, Winner WE. Photosynthetic differences between saplings and adult trees: an integration of field results by metaanalysis. Tree Physiol. 2002; 22: 117-127.

36. Wei L. Disanthus cercidifolius var. longipes. Bull Biol. 2015; 50(5): 3.

37. Wright IJ, Reich PB, Westoby M, Ackerly DD, Baruch Z, Bongers F, et al. The worldwide leaf economics spectrum. Nature. 2004; 428: $821-827$.

38. Wu RL, Hu JJ, Liu HX, Han YF. How phenotypic plasticity affects crown architecture and development in woody plants. Sci Silvae Sin. 2002; 38(4): 141-156.

39. Xiao YA, He P, Deng HP, Li XH, Shi MZ. Influences of different illumination on photosynthesis of Disanthus cercidifolius var. longipes H. T. Chang seedling. J Southwest China Norm U (Nat Sci Edit). 2003. 28(3): 440-443.

40. Xiao YA, He P, Li XH. The flowering phenology and reproductive features of the endangered plant Disanthus cercidifolius longipes H. T. Chang (Hamamelidaceae). Acta Ecol Sin. 2004; 24: 14-21.

41. Xie GW, Li LK, Zhao JJ, Zheng YS, Li XQ, Zhang JM, et al. Genetic diversity of national endangered plant Disanthus cercidifolius longipes in Nanling. J Guangzhou U (Nat Sci Edit). 2014; 13(4): 47-52.

42. Xie GW, Xu HM, Li XQ, Zheng YS, Teng JH, Tian YN, et al. The species community diversity of the endangered plant Disanthus cercidifolius longipes in Jiangxi and Zhejiang Province. J Guangzhou U (Nat Sci Edit). 2016; 15(4): 33-38.

43. Xie YH, Yu D, Geng XH. Effects of elevated CO2 concentration on phenotypic, physiological and biochemical characteristics of submersed plant Potamogeton crispus leaf. Acta Phytoecologica Sin. 2003; 27: 218-222.

44. Yang DM, Zhang JJ, Zhou D, Qian MJ, Zheng Y, Jin LM. Leaf and twig functional traits of woody plants and their relationships with environmental change: a review. Chin J 2012; 31: 702-713.

45. Yang Q, Li ZZ, Fu Q, Feng JC. Relationship among leaf trait and developing process in populus euphratica. J Desert Res. 2016; 36: 659-665.

46. Yao J, Li Y, Wei LP, Jiang SS, Yang S, Hou JH. Changes of allometric relationships among leaf traits in different ontogenetic stages of Acer mono from different types of forests in Donglingshan of Beijing. Acta Ecol Sin. 2013; 33: 3907-3915.

47. Zhang JM, Liao YY, Xie GW, Liu PP, Tan FF, Lin ZG, Xie XZ. Population characteristics of national rare and endangered plant Disanthus cercidifolius longipes. J Trop Biol. 2013; 4: 74-80.

48. Zhang L, Luo TX, Deng KM, Li WH. Vertical variations in specific leaf area and leaf dry matter content with canopy height in Pinus yunnanensis. J Beijing Forestry U. 2008; 30: 40-44.

49. Zheng Y, Wen ZM, Song G, Ding M. The influence of environment and phylogenic background on variation in leaf and fine root traits in the Yanhe River catchment, Shaanxi, China. Acta Ecol Sin. 2014; 34: 2682-2692.

\section{Figures}



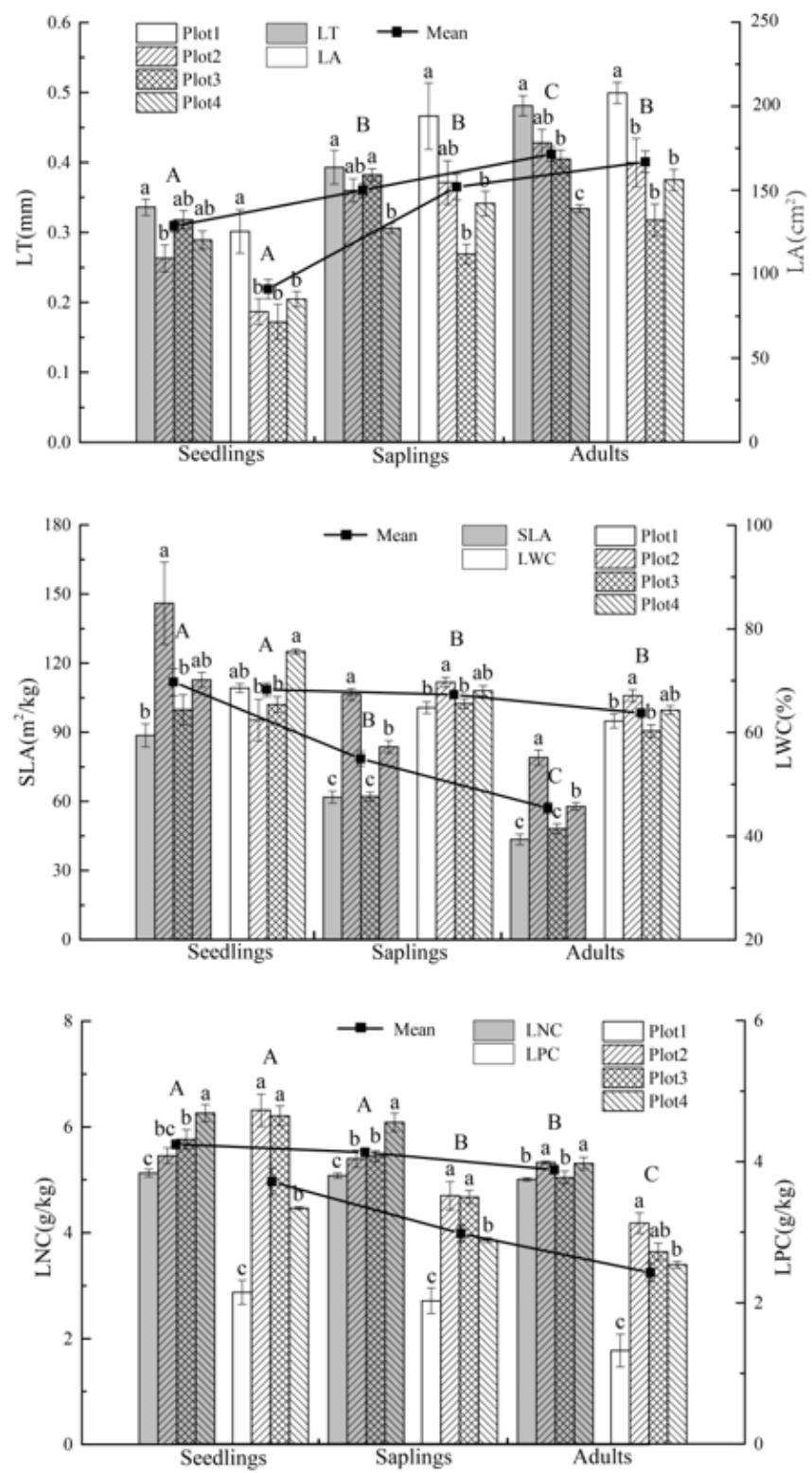

\section{Figure 1}

Leaf functional traits of Disanthus cercidifolius var. longipes at different developmental stages. Note: Different lowercase letters indicate a significant difference between the sampling plots at the same developmental stage $(P<0.05)$; different capital letters indicate a significant difference between the developmental stages across the sampling plots $(P<0.05)$. 


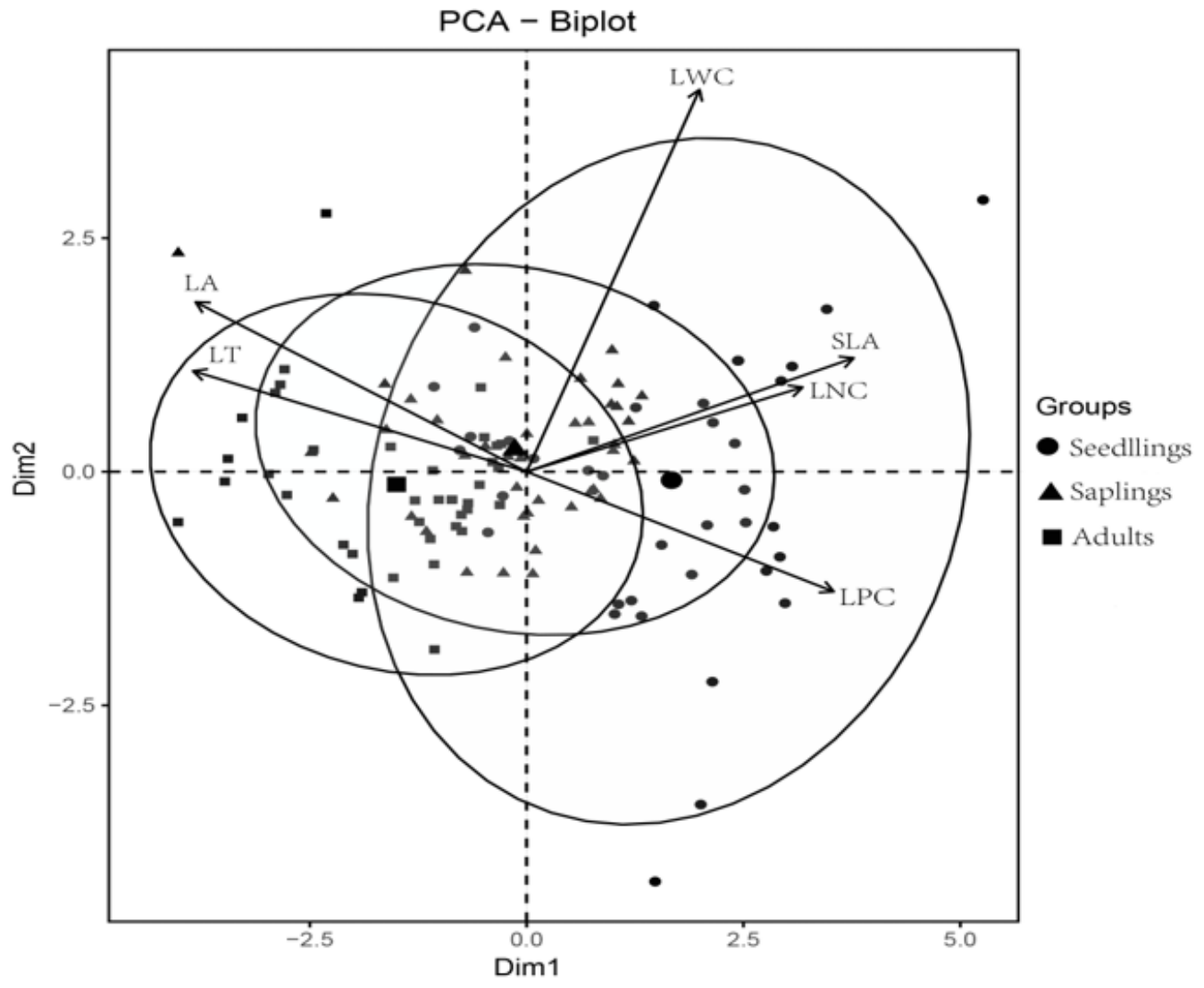

Figure 2

PCA ordination of leaf functional traits of D. cercidifolius var. longipes at different developmental stages. 